\title{
BARIUM AND STRONTIUM FERRITS SYNTHESIZED IN THE SUN FURNACE
}

\author{
Payzullakhanov Mukhammad-Sultan Saidvalikhanovich \\ $D S c$, head of the laboratory for the synthesis and processing of materials of Institute of \\ Material Science of SPA "Physics-Sun" AS RUz, Uzbekistan, Tashkent, \\ Xolmatov Abdurashid Abdurakhim ugli \\ Assistant, Fergana Polytechnic Institute, Uzbekistan, Fergana, \\ Sobirov Muslimbek Muxsinjon ugli \\ Assistant, Fergana Polytechnic Institute, Uzbekistan, Fergana,
}

Article DOI: https://doi.org/10.36713/epra4599

\begin{abstract}
ANNOTATION
Magnetic materials synthesized from a melt in a solar furnace were studied. It is shown that melts consist of crystallites of a metastable structure and an amorphous phase. This state contributes to a directed change in structurally sensitive properties (electrical, magnetic, and optical). It has been revealed that the magnetization values of barium and strontium ferrites synthesized from a melt in a stream of concentrated solar radiation increase 1.8 times in comparison with materials synthesized from solid-phase reactions.
\end{abstract}

KEYWORDS- ferrites, magnetic material, solar furnace, structural defects, magnetization.

\section{INTRODUCTION}

Currently, the question of the synthesis of materials from a melt obtained by exposing a substance to high-density concentrated light radiation, in which compounds are formed during reactions in melts, and then this state is fixed by quenching, is being widely studied [1-4].

Taking advantage of the synthesis of materials by exposure to a concentrated radiant flux (the ability to significantly overheat the melt due to the high power of the furnace, as well as various methods of cooling the melt), the phase composition and microstructure of the final product can be varied, thereby controlling its properties. In addition, the production of ceramic by ceramic technology, in contrast to the widely used glass technology, is currently particularly relevant, since it is less strictly regulated by the chemical composition of the initial glasses, which, in turn, facilitates the production of glass-crystalline materials with a given level of properties [5-6] .

In this work, we studied barium and strontium ferrites synthesized by melting on a solar furnace.

\section{RESULTS AND ITS DISCUSSION}

To obtain ferrous barium oxide, the initial reagents used were barium carbonate $\mathrm{BaCO}_{3} \mathrm{OC} 4$ 93 TY 6-09-351-76, strontium carbonate $\mathrm{BaCO}_{3} \mathrm{OC4}$ 7-2 TY 6-09-01-659-91, iron dioxide $\mathrm{Fe}_{2} \mathrm{O}_{3}$ OC4 2-4 TY 6-09-1418-78. The powders were mixed in the required proportion and briquetted.

Melting a mixture of iron oxide and barium carbonate on the focal plane of a solar furnace under the influence of a concentrated light flux of 350 $\mathrm{W} / \mathrm{cm}^{2}$ density with holding in a melting state for 15 minutes. The melts were coole in air $(102 \mathrm{deg} / \mathrm{s})$ and in running water $(103 \mathrm{deg} / \mathrm{s})$. 


\section{EPRA International Journal of Research and Development (IJRD)}

$\mathrm{X}$-ray phase and $\mathrm{X}$-ray diffraction analyzes of the studied samples were carried out on "DRON$3 \mathrm{M}$ " diffractometers (CuKa - radiation). The radiation wavelength is $\lambda=0.193728 \mathrm{~nm}$. When recording the spectra of the samples, a Mn filter was used. The focusing was carried out according to the Bragg-Bretano method with two Soller slots. The measurements were carried out at room temperature.

The resistivity was measure by the method of current-voltage characteristics and the two-probe method [1]. When conducting electro physical measurements, copper contacts applied by sputtering at the VUP $=3$ installation were used.

The magnetodielectric effect (MD effect, magnetocapacitance) was recorded by changing the dielectric constant when a sample was introduced into a magnetic field

$$
\Delta(\mathrm{H}) / \varepsilon(0)=(\varepsilon(\mathrm{H})-\varepsilon(0)) / \varepsilon(0)
$$

where $\varepsilon(H)$ and $\varepsilon(0)$ are the dielectric constant in the magnetic field and in its absence, respectively.

The magnetodielectric effect was recorded in a constant magnetic field of intensity $\mathrm{H}=3.0 \mathrm{kOe}$.

In the table. Figure 1 shows the properties of barium, strontium, and bismuth hexaferrites that we obtained in this work using traditional ceramic technology and melt synthesis in a solar furnace.

It can be seen that ferrite permanent magnets have a high coercive force, low density, and significant resistivity.

The main characteristics of the samples obtained hexagonal ferrite ceramics

$\mathrm{BaFe}_{12} \mathrm{O}_{19}, \mathrm{SrFe}_{12} \mathrm{O}_{19}$

Table 1

\begin{tabular}{|l|l|c|c|}
\hline \multicolumn{2}{|c|}{ Material } & Coercive force, $\mathbf{H}_{\mathbf{c}}, \boldsymbol{\ni}$ & Magnetoelectric effect \\
\hline \multirow{2}{*}{$\mathrm{BaFe}_{12} \mathrm{O}_{19}$} & solid phase synthesis & 1450 & $2 \times 10^{9}$ \\
\cline { 2 - 4 } & melt synthesis & 2000 & $3 \times 10^{10}$ \\
\hline \multirow{2}{*}{$\mathrm{SrFe}_{12} \mathrm{O}_{19}$} & solid phase synthesis & 2200 & $8 \times 10^{8}$ \\
\cline { 2 - 4 } & melt synthesis & 3500 & $7 \times 10^{9}$ \\
\hline
\end{tabular}

As can be seen from the table, the magnetodielectric effect of materials synthesized from a melt in a solar furnace of compositions $\mathrm{BaFe} 12 \mathrm{O} 19$ and $\mathrm{SrFe} 12 \mathrm{O} 19$ is several orders of magnitude higher than those for samples obtained by ceramic technology. It should be noted that high values of the magnetodielectric effect are 4 times greater in the case of samples of hexagonal barium and strontium ferrites compared with the effect observed on bismuth ferrite samples. The results obtained allow us to conclude that hexagonal barium and strontium ferrites prepared from high-purity raw materials by melt technology, when sintering in air, are excellent high-temperature multiferroics.

It should be noted that in the present work, for the first time, it was possible to realize the manifestation of multiferroic properties in hexagonal barium and strontium ferrites obtained by melt technology. Thanks to this modification of the technological process, it was possible to increase the resistivity of the samples to $\sim 1010 \mathrm{Ohm} \bullet \mathrm{cm}$.

An external magnetic field leads to a decrease in the dielectric constant and an increase in the dielectric loss tangent. The obtained regularities indicate the appearance of magnetostrictive deformation in composites under the action of a magnetic field, which leads to the dielectric response of piezoelectric grains.

Thus, bismuth, barium and strontium ferrites synthesized on the basis of precursors - iron and bismuth oxides, barium and strontium carbonates fused in a solar furnace have a denser structure, low coefficient of thermal expansion compared to traditionally synthesized bismuth ferrite. The technology for creating ceramic materials based on bismuth ferrite requires careful regulation of the physicochemical state of the starting materials.

\section{CONCLUSION}

Therefore, we can draw the following conclusions. First, in the synthesis from a melt in a solar furnace, depending on the cooling conditions of the melt, a glass-ceramic material can be obtained. Such material contains in its composition of the crystallites formed and residual glassy phases, the amounts of which can vary depending on the synthesis conditions.

Secondly, the capabilities of solar technology consisting in overheating of the melt to temperatures much higher than the melting temperature of the raw material, allow to achieve a high degree of homogenization of the melt at the atomic level, which determines the particle size (nano). Thirdly, the crystallite growth rate can be controlled by varying the temperature.

Fourth, the fixation of high-temperature fused states facilitates the production of material with metastable structural formations. Such states will determine the directional change in structurally sensitive properties, primarily electrical, magnetic and optical. 
The features of the synthesis of bismuth ferrite in a stream of concentrated solar radiation of different flux densities are revealed.

It has been revealed that the magnetization values of barium and strontium ferrites synthesized from a melt in a stream of concentrated solar radiation increase 1.8 times in comparison with materials synthesized from solid-phase reactions.

It has been revealed that the magnetization values of barium and strontium ferrites synthesized from a melt in a stream of concentrated solar radiation in a magnetic field increase depending on the strength of the external magnetic field.

\section{REFERENCES}

1. Payzullahanov M.S. Particularities of the syntheses BaTiO3 in the field of concentrated light energy // Horizon Research Publishing, USA Manuscript ID:16200286. 2013. №27.

2. Payzullakhanov M.S., Nurmatov Sh.R., Shermatov Zh.Z. Barium and strontium titanates synthesized in a field of concentrated light energy // Glass and ceramics. 2013, №6, P.123-125.

3. Paizullakhanov, M.S., Faiziev, S.A., Nurmatov, S.R. et al. Synthesis features of barium titanate in the field of concentrated light energy. Appl. Sol. Energy 49, 248-250 (2013). https://doi.org/10.3103/S0003701X13040142

4. Abdurakhmanov, A., Kuchkarov, A.A., Mamatkosimov, M.A. et al. The calculation procedure of the optical-energy characteristics of mirror concentrating systems for technological and energy application. Appl. Sol. Energy 51, 301-305 (2015). https://doi.org/10.3103/S0003701X15040040

5. Payzullakhanov Mukhammad-Sultan Saidvalikhanovich, Xolmatov Abdurashid Abdurakhim ugli, Sobirov Muslim Muhsinjon ugli. Magnetic materials synthesized in the sun furnace // International Journal of Advanced Research in Science, Engineering and Technology. - 2020. Vol.7, Issue 4, - P.149913505.

6. Payzullakhanov Mukhammad-Sultan Saidvalikhanovich, Xolmatov Abdurashid Abdurakhim ugli, Sobirov Muslim Muhsinjon ugli. Barium and strontium titanates synthesized in sun furnace. Universum: Tekhnicheskiye nauki : elektron. nauchn. zhurn. 2020. № 6(75). URL: 4http://7universum.com/ru/tech/archive / item/ 